\title{
Article
}

\section{The effect of a cold environment on physical activity profiles in elite soccer match-play}

Carling, C., Dupont, G., and Le Gall, F.

Available at http://clok.uclan.ac.uk/12291/

Carling, C. ORCID: 0000-0002-7456-3493, Dupont, G., and Le Gall, F. (2011) The effect of a cold environment on physical activity profiles in elite soccer match-play. International Journal of Sports Medicine, 32 (7). pp. 542-545. ISSN $0172-4622$

It is advisable to refer to the publisher's version if you intend to cite from the work. http://dx.doi.org/10.1055/s-0031-1273711

For more information about UCLan's research in this area go to http://www.uclan.ac.uk/researchgroups/ and search for <name of research Group>.

For information about Research generally at UCLan please go to http://www.uclan.ac.uk/research/

All outputs in CLoK are protected by Intellectual Property Rights law, including Copyright law. Copyright, IPR and Moral Rights for the works on this site are retained by the individual authors and/or other copyright owners. Terms and conditions for use of this material are defined in the policies page.

\section{CLoK}

Central Lancashire online Knowledge www.clok.uclan.ac.uk

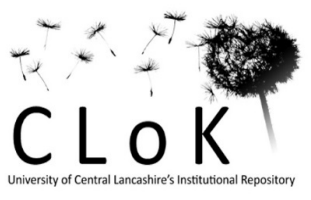


This is a pre-proof corrected manuscript, as accepted for publication, of an article published by Thieme Medical Publishers in International Journal of Sports Medicine on $11^{\text {th }}$ May 2011 available online: https://www.thieme-connect.com/DOI/DOI?10.1055/s-0031-1273711 PLEASE REFER TO THE PUBLISHED VERSION FOR CITING PURPOSES

The effect of a cold environment on physical activity profiles in elite soccer match-play

C. Carling ${ }^{1}$, G. Dupont ${ }^{2}$, F. L. Gall ${ }^{3}$

${ }^{1}$ LOSC Lille Métropole Football Club, Youth Academy, Camphin-en-Pévèle, France

${ }^{2}$ Universite d'Artois, UFR STAPS, LIEVIN, France

${ }^{3}$ LOSC Lille Métropole Football Club, Medical Department, Lille, France 


\begin{abstract}
In this study, the effect of cold temperature on the physical activity profiles of professional soccer players in official match-play was investigated. Computerised motion-analysis was used to analyse performance in 9 players ( 4 defenders and 5 midfielders) in four temperature ranges: $\leq 5^{\circ} \mathrm{C}$ ( 29 matches), $6-10^{\circ} \mathrm{C}$ (62 matches), $11-20^{\circ} \mathrm{C}$ (48 matches) and $\geq 21^{\circ} \mathrm{C}$ (27 matches). Performance was analysed per minute for total distance covered and distance run in three categories: $0.0-14.3 \mathrm{~km} / \mathrm{h}$ (walking/low/moderate); $14.4-19.7 \mathrm{~km} / \mathrm{h}$ (running); $\geq 19.8$ $\mathrm{km} / \mathrm{h}$ (high-intensity). Results showed that while total distance run per minute was unaffected in colder conditions, midfielders ran significantly shorter distances in warmer temperatures: $\geq 21^{\circ} \mathrm{C}=118.7 \pm 6.9 \mathrm{~m}$ versus $\leq 5^{\circ} \mathrm{C}=124.2 \pm 7.1 \mathrm{~m}, \mathrm{p}<0.01 ; 6-10^{\circ} \mathrm{C}=123.6 \pm 6.8 \mathrm{~m}, \mathrm{p}<0.01$; and, $\left.11-20^{\circ} \mathrm{C}=123.4 \pm 5.4, \mathrm{p}<0.05\right)$. The total distance covered at three intensities and across halves was unaffected by temperature. Similarly, high-intensity efforts across match halves and in the first and final 5-minute periods in each half of normal time were unaffected by temperature. In contrast, high-intensity efforts in midfielders across 15-minute intervals were affected by temperature with greater distances covered per minute in the 30-45 minute period in matches played in temperatures $\leq 5^{\circ} \mathrm{C}$ versus the corresponding period in those played in temperatures $\geq 21^{\circ} \mathrm{C}(9.1 \pm 3.8 \mathrm{~m}$ versus $6.2 \pm 3.0 \mathrm{~m}, \mathrm{p}<0.05)$. The present findings generally suggest that physical performance in professional soccer does not decrease in cold temperatures.
\end{abstract}

Key words: performance, temperature, motion analysis, football 
Introduction

Soccer training and competition are often performed by players in unfavourable environments. Indeed, there are three major environmental conditions that raise concerns in relation to soccer performance: high altitude, heat and humidity, and cold [4]. For example, altitude negatively impacts physical performance by impairing aerobic power and delaying recovery of high-energy phosphates between high-intensity "interval" type efforts [14]. Two recent studies [11,13] have also attempted to address the issue of high ambient temperatures on physiological responses and physical activity profiles in soccer competition. A pronounced reduction in high-intensity running was observed toward the end of a friendly game $(-54 \%$ in the final compared to the first 15-minute period) played by professional Spanish soccer players in a hot environment $\left(\sim 31^{\circ} \mathrm{C}\right)$ [11]. Second-half high-intensity running performance in Turkish semi-professional players was also shown to be substantially affected in two games played in temperatures $>30^{\circ} \mathrm{C}$ (mean decrease of 19\%) [13]. Thermal stress and dehydration were factors linked to the drop in performance. However, these studies examined the effects of temperature on performance in one or two matches. The inherent variability in running performance in match-play means that research requires larger sample sizes in order to detect real systematic changes in characteristics of performance [6].

The issue of training and playing soccer in cold conditions has not been studied in a satisfactory manner [4]. A decrease in muscle temperature can affect the ability to produce dynamic explosive contractions [12] inducing significant decreases in sprinting ability [10]. Explanations for impaired muscle performance in the cold include a decreased mechanical efficiency of muscles and vasoconstriction leading to a reduced oxygen delivery [12]. Yet, it is unknown to what extent cold will influence physical activity patterns in intermittent endurance type sports such as soccer. In light of this, information on the impact of playing soccer in cold temperatures on key aspects of performance such as the total distance run and that covered in high-intensity running and on work-rate across different match periods could be useful to inform subsequent preparation strategies. Consequently, the aim of this study in French professional soccer players was to investigate the effect of cold temperatures on physical activity profiles during official competition.

\section{Material and methods}

\section{Participants and match sample}

Physical performance in official competition was analysed for players from a professional soccer team that competed in the French Ligue 1 (top-flight division). While this study meets the ethical standards of the International Journal of Sports Medicine [7], these data arose as a condition of employment in which player performance was routinely measured over the course of the competitive season [15]. Therefore, usual appropriate ethics committee clearance was not required. Nevertheless, to ensure team and player confidentiality, all performance data were anonymised before analysis.

Altogether, performance in 80 French League 1 games over four seasons (2007/2008: N=16, 2008/2009: $N=26,2009 / 2010: \mathrm{N}=26,2010 / 2011: \mathrm{N}=12$ ) was analysed. The sample included 50 home and 30 away matches in which players completed the entire match and played in their customary role. A total of 4 defenders and 5 midfield players were included for analysis leading to 173 and 166 instances of match performance respectively. Forward players were not included due to insufficient numbers of games completed in different temperatures. 
Measures of ambient temperature within a 1-hour period prior to kick-off in French Ligue 1 games are systematically taken by match-day officials belonging to the French Professional Football League [8]. The present measures were subsequently obtained from the League. The following temperature classification was employed: $\leq 5^{\circ} \mathrm{C}=$ very cold, $6-10^{\circ} \mathrm{C}=$ cold, 11 $20^{\circ} \mathrm{C}=$ moderate and $\geq 21^{\circ} \mathrm{C}=$ warm. In defenders and midfielders respectively, 28 and 29 instances of performance were collected at temperatures $\leq 5^{\circ} \mathrm{C}, 70$ and 62 instances at $6-10^{\circ} \mathrm{C}$, 49 and 48 instances at $11-20^{\circ} \mathrm{C}$ and 26 and 27 instances at $\geq 21^{\circ} \mathrm{C}$.

A semi-automatic computerised player tracking system (AMISCO Pro ${ }^{\circledR}$, Sport-Universal Process, Nice, France) was used to analyse physical activity profiles in official match-play. This multiple-camera system passively tracks the movements of every player using a sampling rate of $10.0 \mathrm{~Hz}$ over the entire course of matches. The workings, accuracy and reliability of this system in measuring player movements in elite soccer competition have been described in detail elsewhere [2].

The measures of physical performance selected for the analyses included the total distance covered and the distance covered in three categories of movement intensity: $0.0-14.3 \mathrm{~km} / \mathrm{h}$ (low/moderate); 14.4-19.7 km/h (running); $\geq 19.8 \mathrm{~km} / \mathrm{h}$ (high-intensity) [3]. The overall duration of matches and halves frequently varied. Therefore, all distances covered are presented as the distance covered per minute (distance divided by duration of entire match or individual match period). A drop in high-intensity running performance is frequently observed at the end compared to the beginning of match halves (2). Therefore, distances covered at high-intensities were compared across selected intervals in normal match time: 05mins, 40-45mins, 45-50mins and 85-90mins, and; 0-15mins, 15-30mins, 30-45mins, 4560mins, 60-75mins and 75-90mins.

Statistical Analyses

All statistical analyses were conducted using SPSS for Windows Version 14.0 (SPSS Inc., Chicago, IL, USA). Results are reported as means and standard deviations (mean \pm SD). Twoway ANOVAs were used separately for each playing position to compare overall performance across temperatures ranges and to identify the interactions between temperature and distance covered at various running intensities and across selected match periods. Follow-up univariate analyses using Bonferroni-corrected pair wise comparisons were used where appropriate. Statistical significance was set at $\mathrm{p}<0.05$.

Results

In defenders, the total distance run was similar across all four temperature ranges $(\mathrm{p}=0.135)$ whereas a difference in performance was observed in midfielders $(\mathrm{p}=0.002)$. A longer overall distance was covered by the latter in games played in all temperatures compared to those in temperatures $\geq 21{ }^{\circ} \mathrm{C}$ (see Table 1). Temperature did not influence the distances covered at three individual running intensities in defenders $(\mathrm{p}=0.943)$ or midfielders $(\mathrm{p}=0.271)$.

The comparison of match halves (Table 1) showed that the total distance run varied across halves in defenders and midfielders (both $\mathrm{p}<0.001$ ) as significantly more distance was run in the first- versus the second-half in all temperatures ranges (statistical differences ranged from $\mathrm{p}<0.05$ to $\mathrm{p}<0.001)$. However, performance in each respective half was not influenced by temperature in either defenders $(p=0.439)$ or midfielders $(p=0.685)$. In all temperatures, the distance run at high-intensities did not change between halves in either defenders $(\mathrm{p}=0.269)$ or midfielders $(\mathrm{p}=0.625)$ and performance in each respective half was not affected by temperature (defenders: $\mathrm{p}=0.847$; midfielders: $\mathrm{p}=0.994$ ). 
Insert Table 1 about here.

The total distance covered varied across 15-minute game intervals for matches played in all four temperatures ranges in defenders and midfielders (both $\mathrm{p}<0.001$ ). However, no interaction was observed between temperature and performance across individual match intervals (defenders: $p=0.446$, midfielders: $p=0.125$ ) (Table 2 ). While the distance covered by defenders in high-intensity running across 15 -minute intervals varied for all four temperature ranges $(p<0.001)$ this was not influenced by temperature $(p=0.854)$. In midfielders, the distance covered in high-intensity running across 15 -minute intervals did not vary $(\mathrm{p}=0.413)$ but was dependent upon temperature $(\mathrm{p}=0.009)$ as more distance was covered in the 30-45 minute period in matches played at temperatures $\leq 5^{\circ} \mathrm{C}$ compared to the corresponding period in matches played at temperatures $\geq 21^{\circ} \mathrm{C}(\mathrm{p}<0.05)$. In addition, more distance was covered at high-intensities in the 75-90 minute period in matches played at temperatures from $11-20^{\circ} \mathrm{C}$ compared to the corresponding period in matches played at $6-10^{\circ} \mathrm{C}(\mathrm{p}<0.05)$.

Insert Table 2 about here.

In both defenders $(p=0.038)$ and midfielders $(p=0.016)$, the total distance covered in highintensity running varied across selected 5-minute game intervals in normal time for matches played in different temperatures. In midfielders, a greater distance $(\mathrm{p}<0.05)$ was covered in games played at $11-20^{\circ} \mathrm{C}$ for the first 5 -minutes of play compared to the final 5-minutes of play in normal time of the first half (40-45mins) (Table 2). No significant post hoc differences were obtained in defenders. No interaction was observed between performance and temperature for any of the 5-minute intervals in either defenders $(\mathrm{p}=0.604)$ or midfielders $(\mathrm{p}=0.546)$.

\section{Discussion}

In this study, an investigation into the effects on physical activity profiles of playing professional soccer in a cold environment was conducted. The main finding is that cold weather was not detrimental to overall physical performance (total distance and distances covered at three running intensities) in defenders and midfielders and that first and secondhalf running performance was unaffected in cold conditions. While the total distance covered across 15-minute match intervals was unaffected in colder temperatures, a significant difference in performance in high-intensity running across intervals was observed in midfielders. In contrast, high-intensity running performance in the first and final 5-minute periods in each half of normal time was unchanged in cold temperatures.

In many European countries, soccer is often played in near freezing conditions which are frequently associated with a reduction in core and muscle temperature in participants [14]. Subsequently, characteristics specific to soccer performance such as muscular strength and power output may be affected. Similarly, prolonged exercise in very cold conditions $\left(<5^{\circ} \mathrm{C}\right)$ may also lead to dehydration and reduced high-intensity endurance performance [1]. In this study, endurance performance characterised by the total distance run was significantly related to ambient temperature. However, performance was impaired in hot but not in cold conditions. In addition, the total distance covered at three different speed intensities was unaffected by temperature. These results suggest that overall work-rate activity profiles and the capacity to perform intermittent exercise in these elite players were not adversely affected in cold conditions. The average exercise intensity during soccer match-play is estimated to be $75 \% \mathrm{VO}_{2} \max$ [14]. This intensity may be sufficient to offset the deleterious effects of a cold environment on body temperature as related research showed that performance in endurance 
exercise at an intensity of $70 \% \mathrm{VO}_{2}$ max in a cold environment $\left(4^{\circ} \mathrm{C}\right)$ was similar to that performed in moderate temperatures $\left(11^{\circ} \mathrm{C}\right)$ [5]. Nevertheless, the total distance covered by midfield players was significantly lower in warmer temperatures $\left(\geq 21^{\circ} \mathrm{C}\right)$ partly confirming previous findings $[11,13]$ that warmer environments can have a detrimental impact on workrate performance in competitive soccer.

Research in elite soccer generally shows that players cover lower total distances in the second-half of competition and that physical performance can vary substantially across different periods of the game [2]. In the present players, a reduction in the total distance covered in the second compared to the first half and a significant variation in the total distance covered across 15-minute intervals were common to matches played in all temperatures. However, the differences in total distance run in the second-half and that across 15-minute intervals was not related to temperature suggesting that overall running performance in the second-half and in different periods of the game is unimpaired when performing in cold (and warm) temperatures. This result may be linked to nutritional and/or pacing strategies which enabled the present players to adequately respond to match-play demands throughout [3]. It may also be linked to the physical demands imposed by opponents who also adjusted their physical efforts according to the environmental conditions.

The analysis of high-intensity efforts showed that performance across halves and in the 5minute period at the start and end of normal time in each half was unaffected by temperature. In contrast, high-intensity performance across 15-minute intervals in midfielders was dependent upon temperature. Players covered a significantly greater distance in the 30-45 minute period in matches played at $\leq 5^{\circ} \mathrm{C}$ compared to the corresponding period in those played at $\geq 21{ }^{\circ} \mathrm{C}$. In addition, in games played at lower temperatures $\left(\leq 5^{\circ} \mathrm{C}\right.$ and $\left.6-10^{\circ} \mathrm{C}\right)$, the distance covered by midfield players in high-intensity running progressively increased for each 15-minute period reaching its maximum just before half-time (30-45mins) whereas in moderate $\left(11-20^{\circ} \mathrm{C}\right)$ and warm $\left(\geq 21^{\circ} \mathrm{C}\right)$ temperatures, performance was at its maximum at the beginning of games $(0-15 \mathrm{mins})$ and then progressively decreased until half-time. This result suggests that in cold temperatures, high-intensity running performance in midfielders is to some extent affected at the beginning of games and may only reach its optimum towards the end of the first-half. An investigation into the effectiveness of pre-match warm-up regimens in a range of temperatures is therefore merited as is a study examining the effects of duration and intensity of cold exposure prior to and during exercise as these can impact subsequent physical performance [9].

Limitations of this study included the lack of information on additional environmental factors such as relative humidity and wind-chill and changes in climatic conditions over the course of games. In addition, planning for performance in the cold requires an understanding of the mechanisms underpinning the physiological response [12]. Measures of dehydration, heart rate and thermal responses and the relationship between match activity and fitness test profiles are warranted to provide additional information on the physiological strain specific to competitive play in cold environments. Finally, controlled laboratory simulations of soccer match-play could be conducted in an attempt to determine the effects of individual anthropometric characteristics (e.g., body fat percentage and body surface area) and clothing status (thermal protective garments) when performing in a cold environment.

\section{References}

1 Armstrong LE. Nutritional strategies for football: counteracting heat, cold, high altitude, and jet lag. J Sports Sci. 2006; 24: 723-740 
2 Carling C, Bloomfield J, Nelsen L, Reilly T. The role of motion analysis in elite soccer: Contemporary performance measurement techniques and work-rate data. Sports Med. 2008; 38: 839-862

3 Carling $C$, Dupont $G$. Are declines in physical performance associated with a reduction in skill-related performance during professional soccer match-play? J Sports Sci. 2011; 29:63-71 4 Dvorak J, Racinais $S$. Training and playing football in hot environments. Scand J Med Sci Sports. 2010; 20 (Suppl 3): iv-v

5 Galloway SD, Maughan RJ. Effects of ambient temperature on the capacity to perform prolonged cycle exercise in man. Med Sci Sports Exerc. 1997; 29:1240-1249

6 Gregson W, Drust B, Atkinson G, Salvo VD. Match-to-match variability of high-speed activities in premier league soccer. Int J Sports Med. 2010; 31: 237-242

7 Harriss DJ, Atkinson G. International Journal of Sports Medicine - Ethical Standards in Sport and Exercise Science Research. Int J Sports Med. 2009; 30: 701-702

8 http://www.lfp.fr/corporate/reglements

9 Jett, DM, Adams KJ, Stamford BA. Cold exposure and exercise metabolism. Sports Med. 2006; 36: 643-656

10 Mohr M, Krustrup P, Nybo L, Nielsen JJ, Bangsbo J.. Muscle temperature and sprint performance during soccer matches-beneficial effect of re-warm-up at half-time. Scand J Med Sci Sports. 2004; 14:156-162

11 Mohr M, Mujika I, Santisteban J, Randers MB, Bischoff R, Solano R, Hewitt A, Zubillaga A, Peltola E, Krustrup P. Examination of fatigue development in elite soccer in a hot environment: a multi-experimental approach. Scand J Med Sci Sports. 2010; 20 (Suppl 3): $125-132$

12 Nimmo M. Exercise in the cold. J Sports Sci. 2004; 22: 898-915

13 Ozgünen KT, Kurdak SS, Maughan RJ, Zeren C, Korkmaz S, Yazici Z, Ersöz G, Shirreffs $S M$, Binnet MS, Dvorak J. Effect of hot environmental conditions on physical activity patterns and temperature response of football players. Scand J Med Sci Sports. 2010; 20 (Suppl 3): $140-7$

14 Reilly T. The Science of Training - Soccer. London: Routledge; 2007

15 Winter EM, Maughan RJ. Requirements for ethics approvals. J Sports Sci. 2009; 27: 985

Table 1 Comparison of the total distance run and distance covered at different intensities and between match halves in four temperature ranges.

\begin{tabular}{|c|c|c|c|c|c|c|c|c|}
\hline \multirow{2}{*}{$\begin{array}{l}\text { Distance run } \\
\text { (metres/min) }\end{array}$} & \multicolumn{4}{|c|}{ Defenders } & & \multicolumn{3}{|c|}{ Midfielders } \\
\hline & $\leq 5^{\circ} \mathrm{C}$ & $6-10^{\circ} \mathrm{C}$ & $11-20^{\circ} \mathrm{C}$ & $\geq 21^{\circ} \mathrm{C}$ & $\leq 5^{\circ} \mathrm{C}$ & $6-10^{\circ} \mathrm{C}$ & $11-20^{\circ} \mathrm{C}$ & $\geq 21^{\circ} \mathrm{C}$ \\
\hline Total Distance & $114.0 \pm 6.7$ & $116.0 \pm 6.9$ & $114.7 \pm 6.0$ & $113.3 \pm 6.7$ & $124.2 \pm 7.1$ & $123.6 \pm 6.8$ & $123.4 \pm 5.4$ & $118.7 \pm 6.9^{*}$ \\
\hline 1st Half & $116.1 \pm 7.0$ & $118.4 \pm 7.9$ & $118.4 \pm 7.1$ & $116.9 \pm 6.9$ & $126.5 \pm 7.4$ & $125.3 \pm 7.4$ & $126.2 \pm 7.1$ & $121.0 \pm 8$ \\
\hline 2nd Half & $112.1 \pm 7.9$ & $113.7 \pm 7.4$ & $111.2 \pm 6.9$ & $110.0 \pm 7.9$ & $122.0 \pm 7.9$ & $122.1 \pm 8.2$ & $120.7 \pm 5.3$ & $116.5 \pm 6.6$ \\
\hline $0-14.3 \mathrm{~km} / \mathrm{h}$ & $91.2 \pm 3.5$ & $91.9 \pm 3.5$ & $91.3 \pm 4.0$ & $90.6 \pm 3.6$ & $94.3 \pm 5.2$ & $94.3 \pm 4.2$ & $93.8 \pm 3.5$ & $93.0 \pm 4.9$ \\
\hline $14.4-19.7 \mathrm{~km} / \mathrm{h}$ & $15.6 \pm 2.5$ & $16.2 \pm 3.2$ & $15.7 \pm 2.6$ & $15.0 \pm 2.9$ & $21.8 \pm 4.3$ & $21.2 \pm 3.7$ & $21.3 \pm 3.5$ & $18.1 \pm 4.0$ \\
\hline$\geq 19.8 \mathrm{~km} / \mathrm{h}$ & $7.2 \pm 3.0$ & $7.9 \pm 3.0$ & $7.6 \pm 2.6$ & $7.7 \pm 2.5$ & $8.1 \pm 2.4$ & $8.1 \pm 2.2$ & $8.2 \pm 2.3$ & $7.5 \pm 2.4$ \\
\hline 1st Half & $7.2 \pm 3.1$ & $8.0 \pm 3.3$ & $8.1 \pm 3.3$ & $8.1 \pm 2.5$ & $8.0 \pm 2.7$ & $8.1 \pm 2.8$ & $8.1 \pm 2.5$ & $7.4 \pm 2.7$ \\
\hline 2nd Half & $7.3 \pm 3.5$ & $7.8 \pm 3.8$ & $7.3 \pm 2.5$ & $7.4 \pm 3.0$ & $8.2 \pm 2.9$ & $8.1 \pm 2.4$ & $8.3 \pm 2.8$ & $7.6 \pm 2.9$ \\
\hline
\end{tabular}

\footnotetext{
* Lower total distance covered in matches played by midfielders at temperatures $\geq 21^{\circ} \mathrm{C}$ versus $\leq 5^{\circ} \mathrm{C}(\mathrm{p}<0.01)$, $6-10^{\circ} \mathrm{C}(\mathrm{p}<0.01)$ and $11-20^{\circ} \mathrm{C}(\mathrm{p}<0.05)$.
} 
Table 2 Comparison of distances covered across 15-minute and selected 5-minute match intervals in four temperature ranges

\begin{tabular}{|c|c|c|c|c|c|c|c|c|}
\hline \multirow{2}{*}{$\begin{array}{l}\text { Distance run } \\
\text { (metres/min) }\end{array}$} & \multicolumn{5}{|c|}{ Defenders } & \multicolumn{3}{|c|}{ Midfielders } \\
\hline & $\leq 5^{\circ} \mathrm{C}$ & $6-10^{\circ} \mathrm{C}$ & $11-20^{\circ} \mathrm{C}$ & $\geq 21^{\circ} \mathrm{C}$ & $<5^{\circ} \mathrm{C}$ & $6-10^{\circ} \mathrm{C}$ & $11-20^{\circ} \mathrm{C}$ & $\geq 21^{\circ} \mathrm{C}$ \\
\hline \multicolumn{9}{|l|}{ Total Distance } \\
\hline $0-15 \mathrm{mins}$ & $119.6 \pm 9.0$ & $123.9 \pm 9.4$ & $124.4 \pm 8.8$ & $125.7 \pm 8.3$ & $127.3 \pm 10.3$ & $128.8 \pm 9.5$ & $131.5 \pm 8.7$ & $128 \pm 9.7$ \\
\hline 15-30mins & $116.3 \pm 8.2$ & $116.6 \pm 11.3$ & $115.4 \pm 9.1$ & $114.3 \pm 11.2$ & $126.5 \pm 7.0$ & $124.9 \pm 11.0$ & $123.7 \pm 10.9$ & $119.9 \pm 10.4$ \\
\hline $30-45 \mathrm{mins}$ & $112.3 \pm 9.1$ & $114.1 \pm 9.7$ & $113.4 \pm 9.2$ & $110.0 \pm 8.6$ & $125.2 \pm 9.1$ & $121.0 \pm 10.6$ & $122.1 \pm 10.8$ & $115.2 \pm 10.4$ \\
\hline 45-60mins & $114.7 \pm 9.7$ & $118.4 \pm 9.8$ & $116.3 \pm 7.4$ & $114.8 \pm 13.0$ & $125.0 \pm 12.9$ & $124.6 \pm 17.0$ & $122.6 \pm 7.3$ & $118.9 \pm 11.3$ \\
\hline $60-75 \mathrm{mins}$ & $109.5 \pm 8.6$ & $111.6 \pm 10.0$ & $109.6 \pm 8.5$ & $107.3 \pm 8.8$ & $117.8 \pm 7.1$ & $119.9 \pm 18.1$ & $117.0 \pm 9.1$ & $114.7 \pm 9.5$ \\
\hline 75-90mins & $110.9 \pm 10.4$ & $108.1 \pm 11.2$ & $107.5 \pm 11.0$ & $107.9 \pm 12.0$ & $122.7 \pm 10.7$ & $114.9 \pm 17.1$ & $120.5 \pm 8.7$ & $117.2 \pm 8.7$ \\
\hline \multicolumn{9}{|l|}{$\geq 19.8 \mathrm{~km} / \mathrm{h}$} \\
\hline $0-15 \mathrm{mins}$ & $8.1 \pm 4.6$ & $8.0 \pm 4.7$ & $8.8 \pm 4.8$ & $10.1 \pm 4.0$ & $7.4 \pm 3.1$ & $8.1 \pm 3.9$ & $9.2 \pm 3.7$ & $9.0 \pm 3.0$ \\
\hline $15-30 \mathrm{mins}$ & $7.2 \pm 4.4$ & $8.2 \pm 3.9$ & $7.9 \pm 3.7$ & $7.2 \pm 3.6$ & $7.8 \pm 3.8$ & $8.6 \pm 3.9$ & $8.0 \pm 3.7$ & $7.0 \pm 3.0$ \\
\hline 30-45mins & $6.5 \pm 4.2$ & $7.9 \pm 4.1$ & $7.2 \pm 4.3$ & $7.0 \pm 2.7$ & $9.1 \pm 3.8 *$ & $7.6 \pm 3.9$ & $7.1 \pm 3.3$ & $6.2 \pm 3.0$ \\
\hline 45-60mins & $7.8 \pm 4.0$ & $8.2 \pm 4.8$ & $7.8 \pm 3.6$ & $8.2 \pm 4.0$ & $8.7 \pm 3.5$ & $8.1 \pm 3.7$ & $7.9 \pm 3.9$ & $7.5 \pm 2.8$ \\
\hline $60-75 \mathrm{mins}$ & $6.2 \pm 4.0$ & $7.0 \pm 3.4$ & $6.8 \pm 2.3$ & $7.5 \pm 3.1$ & $8.0 \pm 3.8$ & $8.9 \pm 3.5$ & $7.2 \pm 3.8$ & $7.7 \pm 5.0$ \\
\hline 75-90mins & $7.1 \pm 4.2$ & $6.9 \pm 4.6$ & $7.4 \pm 3.1$ & $7.0 \pm 4.7$ & $7.4 \pm 3.7$ & $7.1 \pm 3.8$ & $9.2 \pm 4.2^{\#}$ & $7.4 \pm 3.7$ \\
\hline $0-5$ mins & $10.1 \pm 6.1$ & $8.9 \pm 7.1$ & $9.0 \pm 8.4$ & $10.1 \pm 5.4$ & $9.8 \pm 6.6$ & $9.4 \pm 6.8$ & $11.1 \pm 7.4 \S$ & $9.5 \pm 6.9$ \\
\hline $40-45 \mathrm{mins}$ & $6.2 \pm 5.8$ & $7.8 \pm 6.5$ & $6.5 \pm 5.5$ & $8.4 \pm 4.4$ & $8.0 \pm 5.4$ & $8.4 \pm 7.5$ & $7.5 \pm 6.2$ & $7.4 \pm 5.0$ \\
\hline $45-50 \mathrm{mins}$ & $7.0 \pm 5.7$ & $8.2 \pm .6$ & $8.6 \pm 7.2$ & $6.4 \pm 5.7$ & $7.6 \pm 4.2$ & $8.9 \pm 5.8$ & $8.5 \pm 6.1$ & $7.3 \pm 4.4$ \\
\hline $85-90 \mathrm{mins}$ & $7.7 \pm 6.5$ & $7.1 \pm 6.3$ & $6.7 \pm 4.8$ & $6.3 \pm 4.8$ & $7.5 \pm 5.8$ & $8.3 \pm 6.1$ & $10.8 \pm 6.7$ & $6.7 \pm 5.8$ \\
\hline
\end{tabular}

${ }^{*} \mathrm{p}<0.05$ : Greater distance covered by midfielders at intensities $\geq 19.8 \mathrm{~km} / \mathrm{h}$ in the $30-45$ minutes period of play in matches played at temperatures $\leq 5^{\circ} \mathrm{C}$ versus corresponding period in matches played at $\geq 21^{\circ} \mathrm{C}$.

$\# \mathrm{p}<0.05$ : Greater distance covered by midfielders at intensities $\geq 19.8 \mathrm{~km} / \mathrm{h}$ in the $75-90$ minutes period of play in matches played at temperatures between $11-20^{\circ} \mathrm{C}$ versus corresponding period in matches played at $6-10^{\circ} \mathrm{C}$.

$\S \mathrm{p}<0.05$ : Greater distance covered by midfielders at intensities $\geq 19.8 \mathrm{~km} / \mathrm{h}$ in the first 5 -minutes of play compared to the final 5-minutes of play in normal time in the first half of games played at $11-20^{\circ} \mathrm{C}$. 